\title{
DUKUNGAN KELUARGA DENGAN KEMANDIRIAN ORANG DENGAN GANGGUAN JIWA (ODGJ)
}

Khamida, Fakultas Keperawatan dan Kebidanan Universitas Nahdlatul Ulama Surabaya

e-mail:khamida@unusa.ac.id

Muhith Abdul, Departemen Keperawatan Sekolah Tinggi IImu Kesehatan Majapahit Mojokerto

e-mail: abdulmuhith1979@gmail.com

Rizkya Dewi Safitri, Fakultas Keperawatan dan Kebidanan Universitas Nahdlatul Ulama Surabaya e-mail: rizkyadewisafitri@yahoo.com

\section{ABSTRACT}

Some families who treat people with mental disorders have fully support their family member, but people with mental disorders do not care about it. ODGJ (People with Mental Disorder) prefer to do what they want to do unless there is an award from the family.

The aim of the study is to find out the relationship between family support and the level of independence of ODGJ in Posyandu Jiwa, Wonokromo Village, Surabaya. The design of this study is analytical with a cross sectional approach. The population is all ODGJ families. The sample is 35 respondents with Purposive Sampling techniques. The independent variable is family support and the dependent variable is the level of independence of ODGJ. The research instrument used a questionnaire. Data analysis using Rank Spearman test.

The results showed that of the 35 respondents most (62.9\%) had good family support and most (65.7\%) were independent. The test results of Rank Spearman statistics $p=0.000<\alpha=0.05$ indicate that there is a family support relationship with the level of independence of ODGJ.

The independence of ODGJ can be achieved to the maximum with good support from the family. It is expected that families can maintain good family support for ODGJ to be more independent and maintain ODGJ's independence, so as not to depend on family

\section{Keywords : people with mental disorder (ODGJ), family support, independence}

\section{PENDAHULUAN}

Kemandirian adalah kesiapan dan kemampuan seseorang untuk mengurangi diri sendiri dalam semua aspek kehidupan yang ditandai dengan pengambilan inisiatif mencoba mengatasi rintangan yang dihadapi, mencoba mengerjakan sendiri tugas-tugas dengan rutin, mencoba mengerjakan perilaku menuju kesempurnaan dan mendapatkan kepuasan dari hasil kerjanya (Muhith A., 2015). Orang dengan gangguan jiwa (ODGJ) yang sudah pulang dari Rumah Sakit Jiwa biasanya mereka sudah sembuh sosial dan mereka mampu berinteraksi pada orang sekitarnya.

ODGJ dapat dikatakan mandiri apabila ia mampu melakukan aktivitas sehari-harinya tanpa bantuan dari pihak keluarga dan dapat inisiatif untuk melakukan semuanya sendiri. Akan tetapi di Kelurahan Wonokromo didapatkan orang yang sudah pulang dari Rumah Sakit Jiwa masih ketergantungan pada keluarga, dimana keluarga masih membantu untuk melakukan kebersihan badan, membantu untuk mengambil makan dan minum, membantu berpakaian ODGJ tersebut dan aktivitas sehari-hari yang mereka lakukan masih atas bantuan dari keluarganya. Sayangnya apabila dari pihak keluarga sudah mendukung secara penuh, biasanya ODGJ lebih memilih untuk tidak peduli. Orang dengan gangguan jiwa lebih memilih apa yang ingin ia lakukan daripada mendengarkan apa kata orang lain (Rinawati, 2017).

Skizofrenia merupakan masalah global yang menjadi perhatian seluruh dunia. World Health Organization (WHO, 2013) memperkirakanada sekitar 450 jutaorang didunia yang mengalami gangguan jiwa, sedangkan National Institute ofMental Health $\mathrm{NIMH}$ ) menyatakan gangguan jiwa mencapai $13 \%$ dari penyakitsecara keseluruhan dan diperkirakan akan berkembang menjadi 25\% di tahun 2030. Prevalensi gangguan jiwa berat dengan penduduk yang mengalami gangguan mental emosional secara nasional adalah $6,0 \%$ (37.728 orang dari subyek yang dianalisis). Provinsi dengan prevalensi gangguan mental emosional tertinggi adalah Sulawesi Tengah (11,6\%), sedangkan yang terendah di lampung (1,2\%)(Riskesdas, 2013).

Data awal pada bulan Oktober 2017 di Posyandu Jiwa Kelurahan Wonokromo 
Surabaya di dapatkan keluarga orang dengan gangguan jiwa sebesar 35 orang. Peneliti melakukan wawancara pada 5 keluarga. Pada 3 keluarga beliau mengatakan bila waktu mandi tiba, keluarga dengan ODGJ memandikan klien karena bila mandi sendiri ODGJ akan membuang-buang air dan tidak selesai-selesai. Ketika waktu makan tiba, keluarga yang merawat orang dengan gangguan jiwa akan mengambilkan makanan untuk klien karena klien tidak mampu melakukan sendiri dan tidak memiliki inisiatif untuk makan sendiri. Pada 1 keluarga lainnya mengatakan bahwa orang dengan gangguan jiwa tidak mampumelakukan aktivitas seharihari tanpa bantuan, bila melakukan aktivitas hanya mau menulis di kertas.Sedangkan 1 keluarga mengatakan bahwa orang dengan gangguan jiwa hanya mandi 1 kali.

Faktor yang mempengaruhi tingkat kemandirian ODGJ terdapat dua faktor, yaitu faktor internal: kondisi fisiologis dan kondisi psikologis sedangkan faktor eksternal tediri dari: pola asuh, rasa cinta dan kasih, pengalaman dalam kehidupan, dan lingkungan keluarga (dukungan keluarga). Bagi individu yang tidak dapat beradaptasi terhadap perkembangan ilmu pengetahuan dan teknologi ini merupakan ancaman bagi dirinya sendiri. Perasaan yang terancam ini merupakan proses pemecahan masalah, dapat menimbulkan stres yang berkepanjangan dan dapat mengakibatkan gangguan jiwa. Mereka mengalami penurunan kemampuan untuk bergerak, berkomunikasi dengan orang lain, tidak mampu menghadapi realita, tidak mampu melakukan perawatan diri, tidak mampu makan secara mandiri, dan tidak mampu melakukan aktivitas sehari-hari secara mandiri sehingga orang dengan gangguan jiwa ketergantungan pada orang sekitar atau keluarga untuk membantu aktivitas yang dilakukan.

Dukungan dari keluarga sangat diperlukan untuk kemandirian ODGJ karena dengan adanya dukungan dari keluarga, ODGJakan merasa dipedulikan sehingga menjadi jiwa lebih percaya diri dalam melakukan aktivitas sehari-hari dan psikologinya akan tertanam lebih baik. Dukungan keluarga seperti kebiasaan keluarga melibatkan klien dalam kegiatan rutin harian dirumah, kebiasaan keluarga melibatkan klien dalam mengembangkan hubungan sosial, dan kebiasaan kleuarga melibatkan klien dalam pengelolaan lingkungan yang ada disekitar klien. Tujuan penelitian untuk mengetahui hubungan dukungan keluarga dengan tingkat kemandirian ODGJ di Posyandu Jiwa Kelurahan Wonokromo Surabaya.

\section{METODE PENELITIAN}

Desain penelitian ini adalah analitik dengan pendekatan cross sectional. Populasi adalah seluruh keluarga ODGJdi wilayah Posyandu Jiwa Kelurahan Wonokromo Surabaya.Besar sampel sebesar 35 responden dengan teknik Sampling Purposive.Variabel independennya adalah dukungan keluarga dan variabel dependen adalah tingkat kemandirian ODGJ.Instrumen penelitian menggunakan kuesioner. Analisis data menggunakan uji Rank Spearman (Muhith A., 2011)

Sebelum melakukan pengambilan data penelitian, proposal penelitian ini telah dinyatakan Laik Etik oleh komite etik penelitian kesehatan Universitas Nahdlatul Ulama Surabaya melaui Keterangan Laik Etik No.145/EC/KEPK/UNUSA/2018. Setiap calon peserta menerima lembar informasi (menjelaskan karakteristik, alasan, dan aspek kemauan dari penelitian ini), formulir persetujuan atau persetujuan untuk ditandatangani, dan bentuk keluhan. Untuk menjaga kerahasiaan, responden hanya menggunakan nomor kode.

\section{HASIL PENELITIAN}

Tabel 1 Karakteristik Responden berdasar usia, Jenis kelamin, pendidikan dan pekerjaan

\begin{tabular}{clcc}
\hline No & Karakteristik & $\mathrm{F}$ & $(\%)$ \\
\hline 1 & Usia & & \\
& a. $17-25$ tahun & 8 & 22,9 \\
& b. $26-35$ tahun & 11 & 31,4 \\
& c. $36-45$ tahun & 11 & 31,4 \\
& d. $46-55$ tahun & 2 & 5,7 \\
& e. $56-65$ tahun & 3 & 8,6 \\
\hline 2 & Jenis Kelamin & & \\
& a. Laki-laki & 15 & 42,9 \\
& b. Perempuan & 20 & 57,1 \\
\hline 3 & Pendidikan & & \\
& a. Dasar & 11 & 31,4 \\
& b. Menengah & 19 & 54,3 \\
& c. Tinggi & 5 & 14,3 \\
\hline 4 & Pekerjaan & & \\
& a. Tidak bekerja & 6 & 17,1 \\
& b. Wiraswasta & 10 & 28,6 \\
& c. Karyawan swasta & 18 & 51,4 \\
& d. TNI/POLRI/PNS & 1 & 2,9 \\
\hline
\end{tabular}


Tabel 2.Distribusi responden berdasarkan dukungan keluarga.

\begin{tabular}{ccc}
\hline Dukungan Keluarga & $\mathrm{F}$ & $(\%)$ \\
\hline Baik & 22 & 62,9 \\
Cukup & 8 & 22,9 \\
Kurang & 5 & 14,3 \\
\hline Total & 35 & 100 \\
\hline
\end{tabular}

Tabel 3. Distribusi responden berdasarkan tingkat kemandirian ODGJ

\begin{tabular}{ccc}
\hline Kemandirian ODGJ & $\mathrm{F}$ & $\%$ \\
\hline Kurang mandiri & 4 & 11,4 \\
Cukup Mandiri & 8 & 22,9 \\
Mandiri & 23 & 65,7 \\
\hline Total & 35 & 100 \\
\hline
\end{tabular}

Tabel 4 Tabulasi silang hubungan dukungan keluarga dengan tingkat kemandirian ODGJ

\begin{tabular}{|c|c|c|c|c|c|c|c|c|c|}
\hline \multirow{3}{*}{$\begin{array}{l}\text { Dukungan } \\
\text { Keluarga }\end{array}$} & \multicolumn{6}{|c|}{ Kemandirian } & & & \multirow{3}{*}{$\mathrm{P}$} \\
\hline & \multicolumn{2}{|c|}{$\begin{array}{l}\text { Kurang } \\
\text { Mandiri }\end{array}$} & \multicolumn{2}{|c|}{$\begin{array}{l}\text { Cukup } \\
\text { Mandiri }\end{array}$} & \multicolumn{2}{|c|}{ Mandiri } & \multicolumn{2}{|c|}{ Total } & \\
\hline & $\mathrm{N}$ & $\%$ & $\mathrm{~N}$ & $\%$ & $\mathrm{~N}$ & $\%$ & $\mathrm{~N}$ & $\%$ & \\
\hline Baik & 0 & 0 & 2 & 9,1 & 20 & 90,9 & 22 & 100 & \\
\hline Cukup & 0 & 0 & 5 & 62,5 & 3 & 37,5 & 8 & 100 & 0,000 \\
\hline Kurang & 4 & 80 & 1 & 20 & 0 & 0 & 5 & 100 & \\
\hline Total & 4 & 11,4 & 8 & 22,9 & 23 & 65,7 & 35 & 100 & \\
\hline
\end{tabular}

\section{PEMBAHASAN}

Dukungan keluarga ODGJ yang tergambar pada tabel 2 menunjukkan bahwa dari 35keluarga didapatkan sebagian besar $(62,9 \%)$ memiliki dukungan keluarga baik. Keluarga selalu memperhatikan aktivitas klien dan mendukung apa yang dilakukan ODGJ, keluarga selalu memuji ODGJ pada saat dia mau melaksanakan kegiatan seharihari, hal itu dapat menimbulkan rasa kepercayaan diri ODGJ. Menurut (Setiadi, 2008) Dukungan keluarga baik dapat berupa informasi, atau nasehat verbal dan nonverbal, bantuan nyata, tindakan yang diberikan menimbulkan perasaan bahwa kehadiran orang lain mempunyai manfaat emosional atau peran pada yang diberikan dukungan.Berdasarkan hasil kuesioner dukungan keluarga didapatkansebagian besar (54\%) keluarga lebih memperhatikan kondisi ODGJketika sakit. Setiap orang membutuhkan sebuah support dan perhatian, dukungan simpatik dan empati, cinta dan kepercayaan serta penghargaan tidak terkecuali ODGJ sehingga dengan adanya dukungan ini ODGJ berpikir bahwa orang disekitarnya masih peduli dan itu dapat memberi semangat untuk melakukan kegiatan sehari-hari. Menurut (Yusuf, Hanik, Miranti \& Fanni, 2017) Dukungan emosional dan penghargaan adalah kemampuan keluarga untuk memberikan klien perasaan nyaman, dihargai, dicintai, dan merasa diperhatikan seperti apabila klien mengganti pakaian, melakukan pekerjaan rumah tangga, makan, dan minum dilakukan secara mandiri maka dukungan yang diberikan keluarga memberikan pujian atau penghargaan berupa hadiah yang disukai oleh orang dengan gangguan jiwa.

Keluarga telah menyediakan apa yang dibutuhkan ODGJ, dan keluarga telah meluangkan waktu menemani berobat dimana dilihat bahwa hal tersebut dapat menyita waktu bekerja akan tetapi keluarga lebih mendahulukan apa yang dibutuhkan oleh ODGJ sehingga ODGJ merasa dirinya berharga dan hal tersebut berpengaruh positif terhadap perkembangan tingkat kemandirian ODGJ. Hal ini diperkuat oleh (Yusuf,Hanik, Miranti \& Fanni, 2017) dukungan fasilitas adalah kemampuan keluarga memberikan biaya bagi pelayanan kesehatan klien dan bantuan kemudahan akses.

Keluarga juga melakukan dukungan informasi, Hasil penelitian didapatkan sebagian besar (69\%) keluarga mengingatkan ODGJ untuk minum obat. Keluarga selalu mengingatkan klien untuk meminum obat dengan tepat waktu sehingga orang dengan gangguan jiwa (ODGJ selalu mengingat kapan dan berapa butir obat yang harus diminum.Hal ini ditegaskan oleh (Yusuf, Hanik, Miranti \& Fanni, 2017) Dukungan informasi adalah kemampuan keluarga untuk memberikan pengetahuan dan penerimaan klien tentang penyakit atau gangguan jiwa.Jika klien bersosialisasi dan berkomunikasi maka dukungan keluarga yang dilakukan yaitu mengingatkan untuk minum obat, keluarga mengingatkan klien tentang perilaku yang dapat memperburuk keadaannya. 
Tingkat kemandirian ODGJ dapat dilihat pada tabel 3 didapatkan sebagian besar (65,7\%) ODGJ mampu mandiri. Kemandirian merupakan hal yang sangat penting bagi orang dengan gangguan jiwa dikarenakan untuk memenuhi kebutuhan sehari-harinya ia tidak bisa terus menerus ketergantungan pada sekitarnya. Dan untuk mempertahankan ODGJ agar tetap mandiri dengan melakukan latihan secara rutin. Menurut (Muhith A., 2015) kemandirian dipengaruhi oleh beberapa faktor, salah satunya faktor lingkungan. Lingkungan sangat berpengaruh bagi proses pembentukan kemandirian. Jika lingkungan sekitar baik maka akan cepat tercapai secara terarah dan teratur. Hasil penelitian didapatkan hampir seluruhnya (77\%) ODGJ mampu mencuci tangan dan mencuci kaki secara mandiri tanpa disuruh atau dipandu keluarga, sebagian besar (69\%)ODGJ) mampu memakai baju, memakai rok/celana, melepas rok/celana secara mandiri tanpa dibantu atau dipandu keluarga. ODGJ yang mandiri mampu memelihara kebersihan diri karena adanya dukungan keluarga yang selalu melatihkan cara kebersihan diri secara rutin. Menurut (Muhith, A., 2015) untuk melakukan personal hygiene maka diperlukan latihan secara terus menerus, berbeda dengan orang normal yang diajarkan beberapa kali sudah dapat mengerti dan hafal apa yang diajarkan.

Berdasarkan hasil uji statistik terhadap hubungan dukungan keluarga dengantingkat kemandirian ODGJ melalui uji RankSpearman didapatkan $=0.000$ dengan nilai kemaknaan $\alpha$ $=0,05$ yang berarti $\mathrm{p}<\mathrm{\alpha}$ maka $\mathrm{HO}$ ditolak artinya ada hubungan dukungan keluarga dengan tingkat kemandirian ODGJ. Pada tabel 5.7 menunjukkan bahwa dari 22 responden dengan dukungan keluarga baik didapatkan hampir seluruhnya (90,9\%) ODGJ mandiri, hal ini menunjukkan ODGJ yang mendapat dukungan baik dan menyeluruh dari keluarga lebih mandiri dalam melakukan aktivitas sehari-hari dibandingkan dengan ODGJ yang memiliki dukungan keluarga kurang. Hal ini menunjukkan bahwa dukungan merupakan salah satu faktor penting yang dapat mempengaruhi kemandirian pada orang dengan gangguan jiwa (ODGJ).Menurut (MuhithA., 2015) dukungan keluarga yang baik akan mampu meningkatkan kemandirian pasien, begitupun sebaliknya, kemandirian tidak akan tercapai secara maksimal apabila tidak adanya kepedulian dan dukungan dari keluarga

\section{KESIMPULAN}

Kesimpulan dari penelitian ini adalah ada hubungan dukungan keluarga dengan tingkatkemandirian ODGJ. Kemandirian ODGJdapat tercapai secara maksimal dengan adanya dukungan yang baik dari keluarga. Diharapkan keluarga dapat mempertahankan dukungan keluarga yang baik pada ODGJ agar lebih mandiri dan mempertahankan kemandirian ODGJ, agar tidak tergantung pada keluarga.

\section{DAFTAR PUSTAKA}

Friedman, Marilyn M, Vicky R. Bowden, Elaine G. Jones. 2010. BukuAjarKeperawatan Keluarga: Riset, Teori \& Parktik. Jakarta: EGC

Harnilawati. 2013. Konsep dan Proses Keperawatan Keluarga. Sulawesi Selatan:Pustaka As Salam.

Kaplan, HI, Sadock, BJ \& Grabb, JA. 2010. Kaplan-Sadock Sinopsis Psikiatrillmu Pengetahuan Prilaku Psikiatri Klinis. Tangerang: Bina Rupa Aksara

Keliat, Budi Anna, Akemat Pawiro Wiyono, Herni Susanti. 2011. KeperawatanKesehatan Jiwa Komunitas: $C M H N$ (basic course). Jakarta : EGC.

Kusumawati, Farida dan Yudi Hartono. 2012. Buku Ajar Keperawatan Jiwa.Jakarta: Salemba Medika.

Muhith, A., Nasir (2011). Buku Ajar Metodologi Penelitian Kesehata, Yogyakarta: Nuha Medika

Muhith, A. (2015). Pendidikan Keperawatan Jiwa (Teori dan Aplikasi). Yogyakarta: Andi.

Muhith, A. (2016). Pendidikan Keperawatan Gerontik (Teori dan Aplikasi). Yogyakarta: Andi.

Muhith, A. (2018).Aplikasi Komunikasi terapeutikNursing \& HealthYogyakarta: Andi.

Muhith, A., Saputra, M.H., fardiansyah A., (2018). Risk factor of rheumatoid arthritis among Eldely in UPT Panti Werdha Mojopahit Mojokerto distric Indonesia. Medicine: Public health, Evironmental and Occupational Health. Indian Journal of Public health Research \& Development.Indian Journal of Public health Research \& Development, Volume. 9 Number, 6 June 2018, ISSN 0978-0245 (print), ISSN 0976-5506 (Electronic). DOI number: 
5506.2018.00589.2.

Muhith, A., fardiansyah A., Saputra, M.H., Nurmiyati (2018). Analisis of causes Impacts of Early Marriage on Madurese Sumenep East Java Indonesia. Medicine: Public health, Evironmental and Occupational Health. Indian Journal of Public health Research \& Development. Volume. 9 Number 8. First page 412-416. (08 Agustus 2018), ISSN 0978-0245 (print), ISSN 09765506 (Electronic). DOI Number: 10.5958/0976-5506.2018,00944.0.

Mallongi, A., dkk, (2018). The spatial patten and risk factors of leprosy occurence in barru indonesia. Medicine: Public health, Evironmental and Occupational Health. Indian Journal of Public health Research \& Development. Volume. 9 Number 8. First page 1489-1494. (08 Agustus 2018), ISSN 0978-0245 (print), ISSN 0976-5506 (Electronic). DOI Number: $\quad 10.5958 / 0976$ 5506.2018,00943.9.

National Institue of Mental Health (NIMH). 2011. The Numbers Count MentalDisorders in America. https://www.nimh.nih.gov/health/public ations/the-numbers-count-mentaldisorders-in-america/index/shtml.

(diakses pada 10November 2017).

Rinawati, Fajar dan Sucipto.2017. Pengaruh Beban Terhadap Sres Yang DialamiKeluarga Dalam Merawat Pasien Gangguan Jiwa. Jurnal IImu Kesehatan.Vol. 6 No.1 (diakses pada 1 Januari 2018)

Riset Kesehatan Dasar (Riskesdas). 2013. Badan Penelitian dan PengembanganKesehatan Kementrian RI tahun 2013. http://www. depkes. go.id/resources/download/general/Hasil \%20Riskesdas\%202013.pdf.(diakses pada 11 November 2017).

Setiadi. 2008. Konsep dan Proses Keperawatan Keluarga. Yogyakarta: Graha IImu.

Setyani, Isnain Eliza. 2016. "Hubungan Antara Dukungan Keluarga Terhadap Kemandirian Perawatan Diri Pada Anak Retardasi Mental Di Sekolah Luar Biasa C Karya Bhakti Surabaya" Skripsi. Program Studi S1 Keperawatan.Sekolah Tinggi IImu Kesehatan Muhammadiyah Gembong.
W, Gail, Stuart. 2013. Principles and Practice of Psychiatric Nursing. Singapore:Elsevier

World Health Organization (WHO). 2013. Mental

Disorders.http://www.who.int/mental_h ealth/prevalensi/schizophrenia/en/. (diakses pada 10 November 2017)

Yusuf, Ah, Hanik Endang N, Miranti Lorencia I, Fanni Okviasanti. 2017. Kebutuhan Spiritual: Konsep dan Aplikasi Dalam Asuhan Keperawatan. 